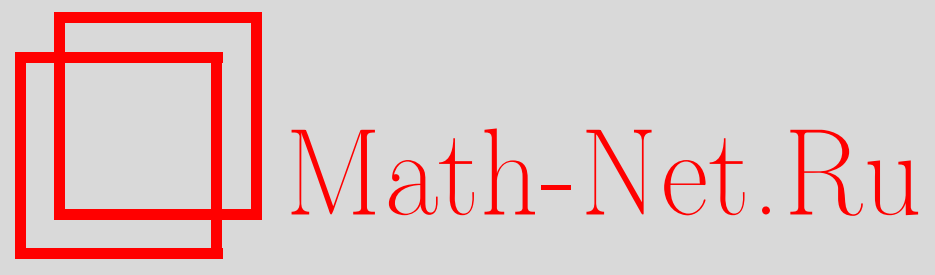

В. П. Маслов, Термо-газо-динамические процессы в АЭС после аварии, Теория вероятн. и ее примен., 2006, том 51, выпуск 3, 583-588

DOI: https://doi.org/10.4213/tvp40

Использование Общероссийского математического портала Math-Net.Ru подразумевает, что вы прочитали и согласны с пользовательским соглашением

http://www . mathnet.ru/rus/agreement

Параметры загрузки:

IP: 3.89 .185 .249

26 апреля 2023 г., 18:30:01

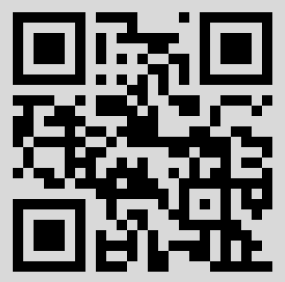




\title{
MISCELLANEA
}

С разрешения академика В. П. Маслова мы публикуем тезисы одного из его недавних выступлений. Я уверен, что эти тезисы будут интересны читателям нашего журнала.

Ю. В. Прохоров

(C) 2006 г.

\author{
МАСЛОВ В.П.*
}

\section{ТЕРМО-ГАЗО-ДИНАМИЧЕСКИЕ ПРОЦЕССЫ В АЭС ПОСЛЕ АВАРИИ}

\author{
Тезисы выступления на заседании Круглого стола \\ «Экологические проблемы энергетики» \\ (Научная сессия Общего собрания РАН «Энергетика России: \\ проблемы и перспективы» 20 декабря 2005 г.)
}

После того, как атомные станции исчерпали свой ресурс, их нельзя остановить. Они продолжают жить. И этот факт «долгожительства» означает, что внутри отслужившей свой век АЭС или АЭС после аварии происходят известные микропроцессы распада, которые мы должны изучить с точки зрения макрофизики, т.е. применить к ним осредненный термодинамический подход.

До сих пор мы были знакомы с несколькими авариями, самой крупной из которых была авария на 4-м блоке Чернобыльской АЭС. Сейчас выработала свой срок Ленинградская АЭС (и дала выброс). Что с ней делать дальше? Решили продлить ее эксплуатацию. На грани окончания срока действия французские АЭС.

Как они будут вести себя после остановки? Ведь экспериментов в лаборатории не поставишь.

Это совершенно новое явление, и мы поставлены перед проблемой, которая никогда раньше не стояла: понять, что заключено в «черном

* Московский государственный университет им. М.В. Ломоносова, физический факультет, кафедра квантовой статистики, Ленинские горы, 119992 Москва, Россия; e-mail: viktor@maslov.msk.su 
ящике» - очень медленно умирающей атомной станции после аварии или после истечения ее срока действия. Не ставит ли этот «черный ящик», опасный для существования всего живого, совершенно новые задачи перед статистической наукой и ее средними (термодинамикой)?

Весной 1986 года меня пригласили собрать и возглавить группу математиков для ликвидации последствий аварии 4-го блока Чернобыльской АЭС.

Огромная ответственность, сжатые сроки, неожиданность некоторых обнаруженных явлений потребовали громадного напряжения наших творческих сил и перевернули мое представление о математике как о науке в целом.

В 1987 году мы опубликовали наш отчет в виде книги [1], но на главные вопросы ответы найдены не были.

Стало ясно, что современная математика должна быть пересмотрена для того, чтобы можно было обобщить и углубить термодинамику, теорию вероятностей и математическую физику - дисциплины, необходимые для решения проблем, возникающих в АЭС после аварий.

Поскольку залезть внутрь разлома и проводить там измерения невозможно, то результаты измерений оказываются осредненными, термодинамическими. Хотя в некоторых отсеках излучения может практически не быть, но опасные пятна внутри разлома будут попадаться достаточно случайно. Для объяснения ряда факторов приходится произвести некоторую ревизию и обобщение термодинамической науки применительно к непредвиденным физическим явлениям. Так как в станции после аварии или после того, как она исчерпает свой ресурс, процессы ядерного деления продолжаются, мы должны применить к этой ситуации точку зрения термодинамической науки, считая время «жизни» станции бесконечно большим.

Вообще пересмотр основных понятий классической термодинамики уже несколько запоздал, так как после открытия сверхтекучести представление о том, что при температуре равной нулю все молекулы останавливаются, было опровергнуто опытом. Поэтому необходимо было изучить явление сверхтекучести с физической точки зрения и с точки зрения математико-физического обобщения. Замечательные результаты школ Ландау и Боголюбова необходимо обобщить так, чтобы их можно было применить к совсем, казалось бы, противоположной ситуации перегрева при аварии АЭС.

Работы физиков, обладающих гениальной интуицией, нуждаются в последующих математико-физических и даже, может быть, философских обобщениях теоретиков такого уровня, как Фок, фон Нейман, Вигнер и другие.

В письмах А.Н. Колмогорова приводится мнение П. Л. Капицы относительно сверхтекучести. Колмогоров пишет: «П.Л. (Капица - BM) 
сообщил следующее: еще перед началом войны им (Капицей - BM) были произведены опыты для проверки теории Ландау. Опыты эти дали результаты (еще не опубликованные), решительно опровергающие все построения Ландау... . Очевидно, задержка опубликования опытных данных для того и устроена, чтобы Ландау свою теорию не успел поправить (так как известно, что "ему ничего не стоит изготовить теорию под любые данные"!)» [2, с. 594]. Последние кавычки, очевидно, относятся к словам П. Л. Капицы.

На самом деле, моментально откликнуться на новые опытные данные - это талант и шаг к истине. А уже связать воедино разные концепции сверхтекучести, классическую термодинамику, теорию осреднений (теорию вероятностей) и данные аварий - это уже задача матфизика. У меня был для этого огромный стимул, поскольку все последние 20 лет после Чернобыльской аварии мне не давали покоя те проблемы, которые не удалось решить тогда, а те переживания, которые я испытал, подписывая разрешение на закрытие саркофага крышкой без полной уверенности, постоянно мучили меня даже во сне. Каждый очередной выброс различных АЭС возвращал меня к этим проблемам.

Для решения этих проблем статистическая физика и наука о ее осреднении в физике - термодинамика, соответственно, математическая статистика и наука о ее осреднении - теория вероятностей должны быть объединены в одну науку.

Однако современная теория вероятностей недостаточна для применения ее к АЭС. Если вероятность аварии пренебрежимо мала, но последствия аварии грандиозны и страшны, то пренебрегать даже «бесконечно» малой вероятностью нельзя.

Второй момент следующий. Приведу математический пример игры в орла и решку. Какова бы ни была предыстория выпадения орла или решки до данного момента, вероятность выпадения орла или решки в данный момент равна $\frac{1}{2}$. Однако, как пишет известный английский физик Р. Пайерлс про рулетку (вместо орла и решки - черное и красное), сомнительно, чтобы «нашелся хоть один игрок, который, рискнув на "черном" один раз, продолжал ставить весь свой выигрыш постоянно на тот же номер... вероятность появления такой "черной" серии настолько мала, что ее следует полностью игнорировать» [3, с. 126]. Как это согласуется с тем, что вероятность от предыстории не зависит?

Эти соображения очень близки к понятию «общего положения» в топологии. Там «общим положением», например, кривой на плоскости относительно проектирования на ось абсцисс, называется такое расположение кривой, при котором «мощность» множества близких кривых с теми же свойствами много больше «мощности» множества кривых с другими свойствами. А это похоже на те соображения, которые продумал Больцман как ответ на возражение Цермело: если из многообразия всех 
возможных начальных состояний взять произвольным образом одно, то крайне невероятно, что оно окажется с убывающей энтропией. Это понятие, близкое к устойчивости, не относится к математической теории вероятностей, но оно обязательно должно присутствовать в новой ревизованной «теории вероятностей», поскольку отвечает вышеуказанному классу проблем.

Отмечу, что общеизвестных понятий в математике, таких как «необходимые условия» и «достаточные условия», недостаточно для решения конкретных проблем АЭС после аварии. Необходимые условия, например, как построить саркофаг, чтобы выброс обязательно случился, написать можно, а сформулировать «достаточные условия», чтобы на $100 \%$ гарантировать, что выброса не будет, более чем сложно.

Как выбрать из множества равноценных конструкций наиболее надежную, «устойчивую»? Эта проблема близка к тому «закону», который приводит Пайерлс, и к понятию «общего положения».

Частотный подход к теории вероятностей предусматривал еще одну важную константу - число испытаний. Колмогоров вернулся к этой точки зрения в работах по теории сложности [4] и увязал это с теорией кодирования.

Например, движение броуновской частицы может быть полностью детерминировано, если учесть движение и столкновение всех молекул среды, в которую она помещена. Тогда алгоритм ее движения будет определяться столь длинным кодом, что можно его считать случайным (см. работы аспирантов Колмогорова [5]). Но нас интересует, как приблизительно будет двигаться частица в большинстве случаев и тот алгоритм с минимальной длиной кода, который описывает это движение.

При тепловом взрыве АЭС невозможно восстановить алгоритм всего процесса, и мы также должны пытаться найти минимальный коды, которые бы описывали различные состояния частей разлома. Именно эмпирическая формула Ципфа-Мандельброта, которую мы пытались применить для определения в 4-м блоке Чернобыльской АЭС лакунарности с:тлава, состоящего из расплавленных твелов, графита и песка, который в силу своей формы получил название «слоновая нога» и по виду носил фрактальный характер. Однако префактор, определяющий лакунарность [6], т.е. величину пустот в «слоновой ноге», явно не отвечал эксперименту. Строгий вывод подобного закона, основанный на обобщении распределения Бозе-Эйнштейна, дал существенное изменение префактора $[7]^{1)}$; см. также [8].

1) Формула Ципфа-Мандельброта для частоты встречаемости $\omega_{k}$, отвечающей рангу $k$, вида $k / k^{0} \sim\left(\omega^{0} / \omega_{k}\right)^{\alpha}$ уточнена в работах [8], [15], [16]: $k / k^{0}=\log (1+$ $\left.\left(\omega^{0} / \omega_{k}\right)^{\alpha}\right)$, где $k^{0}, \omega^{0}, \alpha$ - константы. Это уточнение существенно сказывается на величине префактора и, следовательно, на величине лакунарности. 
Общий термодинамический подход, учитывающий соотношение времени жизни и времени релаксации к квазиравновесному состоянию, асимптотику в общих правилах осреднения, показывает, что между такими явлениями, как фонтанирование сверхтекучего гелия в опыте Аллена-Джонса 1938 года и выбросами в АЭС, есть общее - это не замеченный физиками-теоретиками фазовый переход нулевого рода [9], [10], когда испытывает скачок не только энтропия (или внутренняя энергия - фазовый переход первого рода), но и термодинамический потенциал Гиббса. Момент, в который это может произойти, можно определить из соответствующих уравнений состояний. Этот эффект существенно отличается от известной картины фазового перехода первого рода (ср. рис. 4 в [10]).

Гидродинамический, достаточно медленный процесс был выявлен и в грубом приближении исследован в [1].

Существовало мнение, что твэлы будут расплавлять все, что находится под ними, и проходить сквозь землю в подземные воды, как утюг проходит сквозь лед. Это могло вызвать страшную экологическую катастрофу. Чтобы этого избежать, еще до наших расчетов была сооружена огромная бетонная подушка под завалом, которая должна была препятствовать проникновению твэлов под землю. Однако эта огромная работа была сделана по существу напрасно, так как расчеты показали, что нежелательного эффекта можно избежать.

Мы с покойным В. П. Мясниковым установили, что к данной задаче применимо уравнение типа Дарси, т.е. фильтрационное уравнение. Для ее решения были поставлены эксперименты и проведен большой объем математических расчетов. Оказалось, что даже в случае фильтрации небольшой поддув снизу вследствие разницы давления внизу и наверху завала снижает температуру под твелом. Это подобно каминному эффекту, когда каминная решетка не нагревается, несмотря на очень высокую температуру горящих углей. На практике это подтвердилось: ни один твэл не достиг бетонной подушки.

Трехмерные расчеты, учитывающие конструкцию саркофага и сам гидродинамический процесс «конвекции» в фильтрационной среде, были уточнены позднее в работах [11], [12], [13], а также [14, с. 245-325].

\section{СПИСОК ЛИТЕРАТУРЫ}

1. Маслов В.П., Мясников В.П., Данилов В.Г. Математическое моделирование аварийного блока Чернобыльской АЭС. М.: Наука, 1987, 142 с.

2. Колмогоров. Юбилейное издание в трех книгах. Книга вторая. М.: Физматлит, 2003, $672 \mathrm{c}$.

3. Пайерлс Р. Е. Законы природы. М.: УРСС, 1962, 340 с. 
4. Колмогоров А.Н. Три подхода к определению понятия «количество информации». - Проблемы передачи информации, 1965, т. 1, № 1, с. 3-11.

5. Асарин $E$. A., Покровский $A$. В. Применение колмогоровской сложности к анализу динамики управляемых систем. - Автоматика и телемеханика, 1986, № 5, с. 2533.

6. Мандельброт Б. Фрактальная геометрия природа. М.: УРСС, 2002, 656 с.

7. Маслов В. П. Уточнение закона Ципфа-Мандельброта и лакунарность в идеальном газе. - Теор. матем. физ., 2006, в печати.

8. Маслов В.П. Закон «отсутствия предпочтения» и соответствующее распределение в частотной теории вероятностей. - Матем. заметки, 2006, т. 80, в. 2, c. $220-230$.

9. Маслов В. П. Фазовые переходы нулевого рода. - Матем. заметки, 2004, т. 76, B. 5 , с. $748-761$.

10. Маслов В. П. Квазистабильная экономика и ее связь с термодинамикой сверхтекучей жидкости. Дефолт как фазовый переход нулевого рода. Ч. II. - Обозр. прикл. пром. матем., 2005, т. 12, в. 1, с. 3-40.

11. Маслов В. П. Эффекты перегрева в фильтрационных средах. - Докл. РАН, 1992, т. 326, № 2 , c. 246-250.

12. Маслов В. П., Шафаревич А. И. Точки поворота и положения равновесия скорости конвективного течения газа. - Дифф. уравн., 2005, т. 40, № 5, с. 736-741.

13. Danilov V. G., Maslov V.P., Volosov K. A. Mathematical modelling of heat and mass transfer processes. Dordrecht: Kluwer Academic Publishers, 1995, 316 p.

14. Маслов В. П., Mosolov P. P. Nonlinear wave equations perturbed by viscous terms. Berlin: de Gryuter, 2000, 329 p.

15. Maslov V.P. The Zipf-Mandelbrot law: quantization and an application to the stock market. - RJMP, 2005, v. 12, № 4, p. 483-488.

16. Maslov V.P. Quantum linguo-statistics. - RJMP, 2006 (в печати). 